\title{
PROSODIC CONSTRAINTS ON PRAGMATIC INTERPRETATION: A NEW CHAPTER IN LINGUISTIC PRAGMATICS
}

Petit Mélanie, Nemo François and Létang Camille

Université d'Orléans. LLL.

melanie.petit@u-bordeaux-montaigne.fr

francois.nemo@univ-orleans.fr

camille.letang@univ-orleans.fr

\section{Biography}

Mélanie Petit ended its PHD overseen by François Nemo on 2009 in Orleans' University. It dealt with the links between prosody and words' interpretation. She focused essentially on the analysis of "enfin". She passed one year (2010-2011) in Laval University in Quebec to go further into this theme. Then she worked (2013-2015) as coordinator on Diasmie research program in Orleans which aim was the study of different senses of yes and their specific prosodic realisation.

\begin{abstract}
This paper introduces the importance of prosodic constraints on interpretation in the understanding of the semantic/pragmatic interface and the linguistic marking and lexicalization of pragmatic meanings. It addresses this issue at word and utterance levels, after defining the notions of non-structural prosody and free lexical prosody. At word level, it shows the existence of a prosodic polysemy which lexicalizes into word lexical meanings that include pragmatic orientation, and that prosodic contours/features introduce prosodic comments, typically about the speaker's position toward what is at stake but also about the hearer's expected reaction to this position, forcing their description to be polyphonic. Similarly, at utterance level, it is shown that prosodic comments also occur, and moreover that the scope of such comments is often not the "sentential" meaning. The last section is dedicated to the description of the methodology and techniques used in existing programs to allow the automated discrimination of prosodic forms, and a reliable mapping of prosodic forms with interpretations. Because such a process can succeed only by using large oral data bases and considerably improving semantic/pragmatic descriptions, it is finally argued that the study of prosody is to linguistics and pragmatic linguistics what the microscope was for biology.
\end{abstract}

\section{Key-words}

\section{Pragmatics and linguistics}

In the long-lasting debate between:

- tenants of a non-linguistic ("downstream") conception of pragmatics in which the input of pragmatic interpretation is believed to be the output of an "upstream" semantic (and linguistic) interpretation process;

\footnotetext{
${ }^{1}$ Earlier works on the prosody of enfin are in particular Barnes, 1995; Beeching, 2007; Bertrand \& Chanet, 2005; Buchi \& Städtler, 2008; Cadiot \& al., 1985; Hansen, 2005; Nemo, 2000; Paillard, 2003.
} 
- tenants of an "upstream" conception of pragmatics according to which languages and linguistic constraints are embedded in pragmatic (and interactional) constraints, and completely shaped by them,

our aim today will be to question the importance of prosodic constraints on interpretation, and to show that their study allows simultaneously to:

- comfort the upstreamers hypothesis;

- falsify the downstreamers vision of interpretation;

- open (or enlarge) a new chapter in Linguistic Pragmatics.

by demonstrating that:

- because only uttered sentences (or words) are interpreted;

- because all uttered sentences (or words) are realized with a (free) prosodic intonation which imposes provable constraints on the interpretative process;

- because such prosodic contours are indisputably linguistic drivers of interpretation which are present at the very start of the interpretative process;

- because prosodic contours can be proven to convey fine-grained interlocutive and nontruth conditional information;

- because prosodic contours may also be proven to affect propositional interpretation

they are central both to the field of linguistic pragmatics and to any understanding of the nature of the interpretative process.

We shall assume also that interpretation may ultimately be described in terms of satisfaction of a set of linguistic and non linguistic constraints (Nemo, 2010) and that regardless of the way linguistic and non-linguistic constraints interfere (or not), it is possible to assume that any linguistic driver - no matter if it is a lexical, grammatical, constructional or prosodic driver (or a mixture of those) - which impose constraints on interpretation may convey pragmatic information. In other words, we shall show that the idea according to which linguistic meaning could or should be reduced to syntactically-driven truth conditional interpretation is flawed by the fact that:

- the (linguistic or non-linguistic) nature of the means used to communicate something is completely independent of the nature of the content of what is communicated;

- non-structural prosody (NSP) is fully linguistic but routinely conveys pragmatic information,

with the result that the study of NSP fully belongs to linguistics - and semantics when defined as the study of the linguistic drivers of interpretation - and to pragmatics - once acknowledged that pragmatic information may be provided by linguistic drivers.

\section{Prosodic constraints on interpretation}

Because the terms of prosody or lexical prosody are ambiguous between different readings, notably when it comes to the existence of both lexicalized and structural prosodic features with no effect on whatsoever on interpretation and lexicalized and non-structural prosodic features which directly affects the interpretative process (see Petit, 2009; Calhoun, 2012; Lacheret, 2013; Noda, 2005), it is important to label and define precisely these last features.

As a result, Non-Structural Prosody (NSP from now on) will be defined as: "toute forme libre de réalisation intonative d'une séquence linguistique de quelque nature que ce soit à même d'exercer une contrainte sur l'interprétation (à quelque niveau que ce soit). »(Nemo and Petit, 2015) / « any form of prosodic realization of a linguistic sequence of any kind which is free and capable of coercing interpretation (at any interpretative level). (Nemo and Petit, 2015).

And «free lexical prosody ( FLP from now on) will be defined as: «toute forme libre de réalisation intonative d'une unité lexicale conduisant à donner à un emploi de cette unité lexicale une interprétation à la fois spécifique et réitérable. » (Nemo and Petit, 2015) / «any 
free form of prosodic realization of a lexical unit which associates one of its uses with both a specific and recurrent interpretation» (Nemo and Petit, 2015). As such, it must be distinguished from classical notions such as word stress or lexical stress, which refer to prosodic features which are compulsory and do not encode any constraint on interpretation.

It follows from this that an utterance will always be defined as syntactic sentence/NSP pair, and that such pairs must be considered by the linguists as the minimal authentic linguistic unit which they must consider. In other terms, it must be understood that as far as linguistics and interpretation are concerned, the fact that ordinary orthographical (or phonematic) transcriptions completely ignore and mask NSP is both a problem and an illusion.

Similarly, it must be understood that because at word-level, FLP (Free lexical prosody) is most often lexicalized, it is also an illusion to postulate the existence of a lexicon in which word/meaning pairs would be free of a FLP contour (cf. Nemo and Petit, 2011).

Proving the existence of both NSP and FLP may be achieved through different methods. A preliminary approach consists in the creation of tests of perception, typically by extracting the prosodic realization of the linguistic sequence at stake (e.g. word use or sentence use) from authentic data and by testing the capacity of the participants to spell out stable features of the context of use. In other words, even though the participants have no idea nor access to the exact nature of the context of use of the sequence, they most often prove to be perfectly able whenever a prosodic contour is associated with the sequence - to describe intersubjectively valid features of the type of situation (or context) in which it is used (see Nemo and Petit, 2011 about the lexicalization of context-types).

Non-structural prosody (NSP) is thus not equivalent to intonational meaning - which is usually defined as "the use of suprasegmental phonetic features to convey "post-lexical" i.e. sentence-level pragmatic meanings in a linguistically structured way » (Ladd, 2008) primarily because it occurs routinely at a non-post lexical level (i.e. at word-level) and at various discourse post sentential levels (e.g. discursive sequences or macro-syntactic ones) but also because NSP as a discourse modifying device (see Nemo, 2006a, 2007, forthcoming for a definition of discourse modifiers) actually does not-modify a sentence-level meaning but only utterances or contributions.

\section{What is prosodically said about what is said}

Moreover because "what is prosodically said about what is said" is crucial to the interpretation of "what is said", it is necessary for linguistic pragmatics to address this issue in great detail.

\subsection{Lexicalized FLP and prosodic polysemy}

If we consider some of the numerous uses of French enfin, it is possible to isolate an "interpretation-type" of enfin in which it is used when a problem at stake has just been solved and which used to be called the "relief" enfin (Nemo, 1999) prior to the study of its prosodic form. Such a study (Petit, 2009) has indeed shown that within this shared interpretation, however, the prosodic realization actually led to two distinct "use-types", one expressing relief (phew !) about the outcome and one expressing a rest of anger that it took so long to solve it. In other words, it may be the case that a problem has been solved, but in such a situation French people either express prosodically their relief about it (as expected) or residual irritation about it which can be paraphrased as a "it was more than time" prosodic comment, as shown in the following example:

\section{Enfin prosodic comment « it was more than time »}

(1)Journalist1: euh Sud-Ouest s'intéresse aujourd'hui à la ligne ferroviaire PauCanfranc et au début des travaux entre Oloron et Bedous. (euh The Sud-Ouest 
newspaper is interested today by the Pau-Canfranc railway line and the start of travaux between Oloron and Bedous.)

Journalist2: oui c'est enfin le début c'est très exactement aujourd'hui à 15 heures le début officiel en gare de Lurbe Saint-Christau.(yes, it is finally the start it is exactly today at $3 \mathrm{pm}$ their official start in the Lurbe Saint-Christau railway station).

However, prosodic contours of irritation are not limited to this interpretation-type and it may occur in another interpretation-type of enfin (classically labeled irritation enfin) when someone is protesting about an on-going problem and asking for the problem to be stopped:

\section{Enfin protestative prosodic comment « how can anyone say that? »}

(2)Journalist: ne passez pas si vite s'il vous plaît (do not pass so quickly please) Agriculture Minister: mais si mais si (I sure will)

Journalist: non la loi Macron on nous a expliqué depuis quelques semaines qu'au fond c'était la loi qui allait relancer la croi la croissance c'était la loi activité et puis (no, the Macron's law we have been explained for a few weeks that it was the law that would boost growth, that it was an activity law, and then ...)

Agriculture Minister: mais il faut arrêter avec ces idées que la croissance parce qu'on vote une loi mais enfin dans quel pays sommes-nous? (but we have to stop with this idea that the growth because we vote a law, come on but what country is this ?)

And it can ultimately be shown that the only way to describe the anchoring and lexicalization of such prosodic contours in the polysemy of a given word is to adopt a representation of lexical structures adopting use-type level as a base and a dual representation of both the phonological form and the semantic interpretation (Nemo and Petit, 2012)

Use-type:

$\begin{array}{ll}\text { Phon: } \sigma & \varphi: \text { value (phonematic form) } \\ & \pi: \text { value (prosodic form) } \\ \text { Sem: s } & \psi: \text { value (interpretation-type) } \\ & \rho: \text { value (comment) } \\ \text { Grammatical status } \gamma: \quad \text { value }\end{array}$

Importantly, such a reality is not limited to specific items such as enfin, as may be shown by the prosodic study of the French quelques (i.e. some) whose pragmatic orientation has been discussed for decades prior to the study of its FLP.

Despite being presented in Ducrot $(1973,7)$ as oriented towards a positive conclusion in an utterance such as "il a lu quelques romans de Balzac" ("He has read some of Balzac's novels"), quelques appears to be most often paraphrased by peu ("little") in dictionaries (Gaatone, 1991, 3) ${ }^{2}$ predicting that its orientation should be negative. And accordingly, one may observe a constant oscillation in all the existing linguistic work between claims that quelques characterizes a limited quantity as positive (Gondret,1976,149; Gaatone,1991,9) and claims of a characterization of a quantity as negligible (Paillard, 2002) with Bacha $(1997,54)$ insisting on the fact that "choosing between quelques and plusieurs for a quantity which may be identical in both cases, is a matter of orienting the interpretation and the conclusion of the interlocutor respectively toward the negative or the positive".

\footnotetext{
2 "The seme «peu élevé » is used almost unanimously in the definition of quelques, by both dictionnaries and standard French grammars.". "peu élevé", when referring to a quantity, means "low amount".
} 
However, once tested, it appears that the role of FLP prosody in the determination of this pragmatic and argumentative orientation is crucial, and that it plays an interpretative role at three levels:

- it appears that with the right prosodic realization, it is possible for quelques to present a quantity as a significant one, deserving full consideration, exactly as it is possible to present it as negligible, with another prosodic contour;

- it also appears that when the first syllable is realized with a variation of intensity, it indicates (Petit, 2009) that the quantity at stake should receive full attention, and this regardless of the exact nature of the positive or negative orientation. In other words, this contour is associated with the marking of the scalar slope in the sense of Nemo $(1992,1999)$, i.e. with signaling that the difference something makes is important;

- it finally appears that apart from the marking of the scalar slope on the first syllable, marking the quantity as significant is achieved by adopting a high-pitched melody for the quelques segment (contrastively with the rest of the sequence).

In other words, the problem is not to know whether quelques as a word is encoding a certain pragmatic orientation and which, as assumed by all the above mentioned authors, but to acknowledge the existence in the polysemy of quelques of different use-types, each of which being associated both with a specific prosodic form $\pi$ and a specific comment $\rho$, and presenting the quantity at stake either under different perspective ${ }^{3}$.

\subsection{NSP at utterance level}

Moving now to NSP at utterance level, we shall show not only that prosodic contours are an undisputable part of what is said, but also that what is prosodically commented is often not the propositional interpretation of the uttered sentence, much has to be reconsidered in the received understanding of the nature of the semantics/pragmatics interface at that level.

Let us consider the utterance "il n'y a pas mort d'homme" (i.e. «nobody's dead ») in French. As a proposition, it describes the fact that nobody died. As an utterance, it might be uttered in a variety of situations, one of which being a situation in which something problematic has happened and in which the utterer recalls that nobody is dead in order to minimize what has taken place. This use, which has conventionalized enough in French as to become the standard/default use of the sentence, is associated with a prosodic contour of minimization, which we shall call the "it's no big deal" prosodic contour/comment. The important point about all this is that when it comes to defining what the utterance/utterer actually says, in other words to defining "what is said", it can be proved as we shall see that people actually do not care at all about the propositional content of the utterance, but only about the "it's no big deal" prosodic assertion (so to say) which linguists would tend to describe as a pragmatic implicature of what is said, but which proves instead to be a prosodic implicature of the material way what is said is said.

Confronted with such simple observation, the classical opposition between "sentence meaning" and "speaker's meaning" is hence due to collapse. And this not only because the expression of the speaker's attitude ("it's no big deal") toward something proves to be literally marked in the prosodic realization of the sentence, with the result that the speaker's meaning becomes an inherent part of the (uttered) sentence meaning, but also because the notion of "sentence meaning" itself becomes ambiguous between two-readings ("intoned sentence" or "non-intoned sentence") and that it can (as mentioned) be proven that what hearers consider as the meaning of the sentence is indeed the meaning of the uttered intoned sentence and not the meaning of an non-uttered non-intoned sentence: in the context of the Dominique Strauss-Kahn rape scandal, it could be observed that if the uttering of " il n'y a pas

\footnotetext{
${ }^{3}$ It is worth noticing that more «neutral » prosodic comments can be made, and that they are so to say neutral both in terms of intonation and in terms of pragmatic comment.
} 
mort d'homme" (no one is dead) by ex-Minister Jack Lang was considered as shocking and eventually forced him to have to explain and excuse himself, it is not because of the propositional content of the utterance, namely that nobody had died, a reality which in itself was completely uncontroversial and never came to be a topic of discussion in the public controversy at stake, but because of the "it's no big deal" prosodic comment associated to it: prosodic comments must thus be considered as a full and salient part of what the speakers are actually saying and what hearers are actually understanding, and moreover are a part of the message which simply cannot be cancelled.

This reality can easily be proven by another declaration about the DSK scandal which also provoked outrage among the general public and eventually led to its author, Jean-François Kahn, to resign as director of a newspaper. It consisted in saying " $c$ 'est du troussage de domestique" with the same "it's no big deal" comment. The important point is that apart from the somehow old-fashioned vocabulary being used, it can be observed on the one hand that the propositional content was once again undisputable, and on the other hand that if the same sentence had been uttered with a "this is deeply shocking" prosodic contour, no controversy whatsoever would have emerged, proving that it is indeed the prosodic comment alone which led to it and that speakers have no option but to take full responsibility of the prosodic form associated with their statements. It hence follows that prosodic comments at utterance level are an inherent and non-cancellable part of the social understanding of what is said. As such, and because they most often mark the relationship of the speakers toward what is at stake, and because having a certain relationship towards what is at stake is inevitable (even if it may be concealed by the non-sincere manifestation of another form of relationship), such comments are both fully pragmatic and fully linguistic. Studying the prosodic profiling of utterances thus deserve to become a chapter of linguistic pragmatics.

A crucial point which needs finally to be highlighted is the fact that even though a complete material description of the uttered/intoned sentence imposes, as already mentioned, to describe it as a sentence/prosodic contour pair, which can be noted (s, $\pi$ ), and because this $\pi$ contour can also be described as a prosodic comment, it is not the case that the $\pi$ comment is commenting the content associated with sentence s: in our two examples, one may indeed observe straightforwardly that the "it's no big deal" comment is a not at all a comment of the fact that nobody died, which would imply to say "it's no big deal that no one died", but a comment about what happened whose association with the interpretation of $\mathrm{s}$ is actually " $i t$ ' $s$ no big deal since no one died" with s providing a justification for the claim that "it's no big deal". Whereas in our second example, the reading of the utterance is slightly more ambiguous, given that the speaker is primarily backing the idea that "Le troussage de domestique is no big deal" but ultimately in order to say that "what happened is no big deal since".

It is important thus to realize that the role of prosodic contours is basically to introduce a comment which will be associated with all other constraints on interpretation to produce the final interpretation of what the utterance says but that the question of knowing whether this comment is about what the uttered s says or not is basically undefined: it may be the case for a furious teenager to say "I am not three years old" because (s)he consider that (s)he has been treated as if (s)he was, but in such a case the scope of the irritated $\pi$ contour is not the fact of not being three years old but the fact of not being treated as such.

\subsection{Commenting the interlocutive scene}

Even though studying NSP/FLP at utterance or lexical level is somehow different, especially as we shall see in the next section in terms of the techniques used for such a study, it must be

\footnotetext{
${ }^{4}$ The expression was translated as "stripping or having casual, forced sex with a servant" by Wikipedia.
} 
stressed out that as far as interpretation is concerned, there is in some sense no encapsulation whatsoever of prosodic comments with such or such interpretative level. And it is extremely easy to observe (and test through perception tests) that the prosodic realization of a word for instance is actually providing fine-grained information about the interlocutor's expected relationship with what is being said, and furthermore about the speaker's position in regard of the interlocutor's expected reaction. So that ultimately, prosodic contour at word level are routinely mirroring what we propose to call the interlocutive scene, projecting a strongly dialogical and polyphonical information on a lexical segment.

An interesting aspect of the prosodic study of uses of a word like "oui" (yes) is not only that one may observe that because of their prosodic realization, it is frequently the case for a "oui" use to actually mean " $n o$ " or at least to mark a form of reluctance, but it is also the case as we just mentionned that the prosodic contours associated with oui routinely mirror the anticipation of an expected reaction of the addressee and hence imposes a polyphonic description, in the sense of Ducrot and the Scapoline school, of the prosodic comment.

For example, and with the limitation here of having no means to make hear the contours at stake, in an exchange ${ }^{5}$ between politicians such as (3), the sole prosodic contour of the word oui will allow any hearer to predict that what is being discussed has been criticized and that the speaker has chosen to proudly stand to it, and thus to paraphrase it as « i proudly assume a position which I know has been contested »:

(3) Nous nous préférons financer des emplois-jeunes qui vont effectivement travailler dans des tâches d'utilité collective plutôt que de continuer à subventionner comme vous le faisiez des emplois qui pouvaient être solvabilisés comme l'on dit par le marché alors oui nous préférons créer 350000 emplois-jeunes et moi je suis plutôt fier que on ait pu donner à des jeunes qui aujourd'hui attendent un emploi eh bien cette perspective de s'insérer dans la société française.

(We we prefer to finance youth-jobs which are indeed dedicated to tasks with a collective utility rather than keeping subsidizing, as you did, jobs that could be funded by the market, so yes we prefer to create 350000 youth-jobs and I am rather proud that we were able to give to young people which nowadays are looking forward a job, indeed this perspective to find a place in the French society.)

A similar posture will be expressed in example (4) by a right-wing politician, by the prosodic comment on oui, which can be paraphrased roughly as "I know that what I am going to say will be described as xenophobic but I am firm on this":

(4)On dit que lorsque des Roms qui sont des étrangers qui ne sont pas en règle qui ne $n$ 'ont pas le droit de demeurer dans notre pays sans apporter un certain nombre de garanties on aurait désormais l'obligation de les loger de scolariser leurs enfants alors qu'on n'apporte même pas des réponses concrètes aux Françaises et aux Français alors oui je dis qu'il y a un vrai problème et que nous ne devons pas accepter que ni la Roumanie ni la Bulgarie ne rentre dans le périmètre de Schengen.

(When it is said that Roms who are strangers, irregulars, with no right to stay in our country without some safeguards, we would have the obligation to give them a roof, to school their children when we don't even give concrete to French women and men, so yes I am saying that there is a real problem and that we should not allow neither Romania nor Bulgaria to enter the Shengen perimeter.)

\footnotetext{
${ }^{5}$ A summarized translation of (3) would be « We have preferred to finance $\mathrm{X}$ and not $\mathrm{Y}$ (as you did), and yes, despite the criticisms about it, we shall stick to it and we shall be proud of it".
} 
Contrastively, one may also observe uses of oui such as (5) and (6) whose prosodic contours are paraphrasable by something such as "yes and no, one cannot really say that":

(5)- il s'agit en fait de frais de clôture c'est ça parce qu'on clôture le le compte euh naturellement de la personne qui est décédé. (it concerns closure costs, that's it because when you close the account euh naturally of the deceased person)

- oui bah disons ils on l'annonce pas comme ça on parle de frais de succession dans les notices tarifaires. (yes, well, let's say that they it is not announced like that one talks about succession fees in the cost sheets)

(6)- Quel job ingrat quand même non? Porte-parole du Gouvernement. (What a thankless job, no ? Government spoke person.)

- oui of. (yes, of $\left.{ }^{6}\right)$

But apart from identifying the nature and the diversity of the prosodic comments, any linguistic study of NSP at such a stage imply to try to identify the prosodic contours or prosodic features which allow the hearers and the linguist to access to the kind of information and comments which for instance are predictable from perception tests. In other words, mapping the interpretation of prosodic contours or features with the prosodic nature of these prosodic contours is the next step in the study of NSP and FLP.

Such a step however is not an easy one to achieve, for both technical and methodological reasons. As far as linguistic pragmatics is concerned, the main problem is the following: any specialist of prosody will tell you that comparing prosodic features requires among other things recording conditions which cannot be met outside of a laboratory and ideally, minimal pairs. But it is also the case that the kind of data which is necessary for the study of NSP and FLP cannot be obtained in the artificial conditions of a laboratory and that such conditions can easily produce prosodic artifacts. Working on the diversity of word and utterance uses requires authentic data extracted from a variety of sources and in distinct recording conditions, with the certainty of variation of essential parameters.

Knowing all this, and thus that proving the association of specific prosodic features with specific interpretations is in such conditions scientifically problematic, it is nevertheless possible to try to catch robust correlations, for instance by superposing the prosodic contours of our four oui examples, as in figure 1:

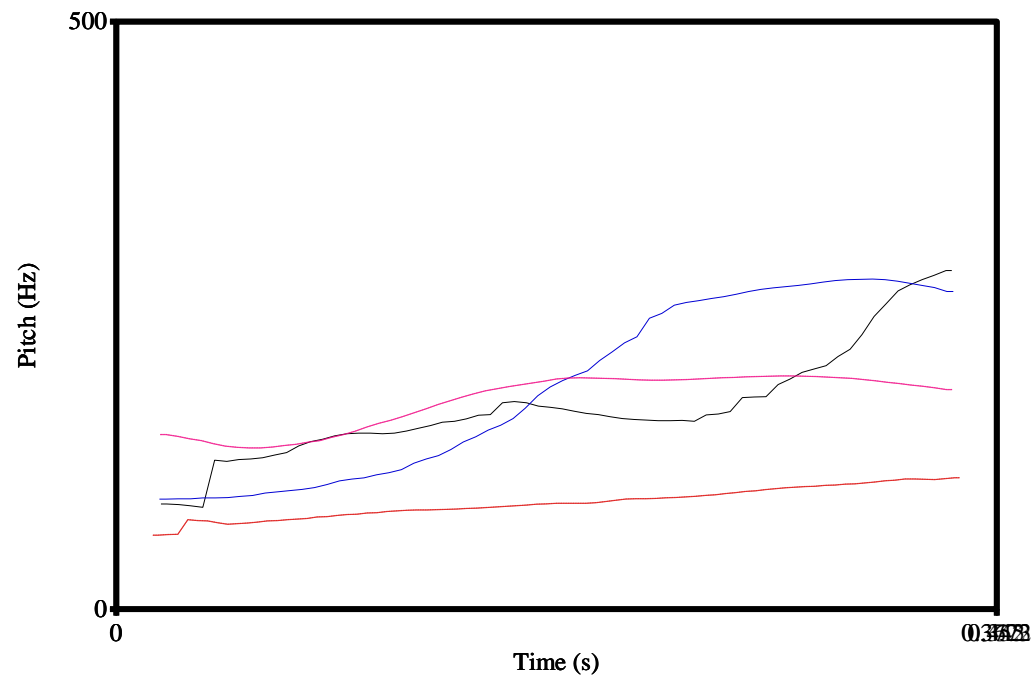

\footnotetext{
${ }^{6}$ This of is not a fully recognized French lexeme, even if its existence is beyond doubt. In this context, it is interpreted as something like "in my position complaining would be misplaced", which serves as a way to avoid any complaining interpretation of the "yes" answer.
} 
Figure 1

The upper (full and black) line on the right is our example (3), a convinced use of oui. The second upper (full and blue) line on the right is example (4), a convinced use of oui. The second lower (dotted and orange) line on the right is example (5), an unconvinced use of oui. The lower (dotted and red) line on the right is example (6), an unconvinced use of oui.

(s)he can then try to figure out which prosodic variation is associated with which information and can often make correct conjectures ${ }^{7}$ about form/meaning pairs, as for instance here by spelling out the differences between the two upper lines (starting on the right) whose prosodic comment is associated with the expression of conviction, and the two lower lines.

With the necessity to compare enough data to make the comparison reliable, a four steps procedure can be developed:

- step 1 is to study semantic variation regardless of any consideration of prosodic contours;

- step 2 is to study prosodic variation regardless of any consideration of semantic interpretation;

- step 3 is to shuttle between prosodic characterization and semantic characterization, either by studying the diversity of prosodic realizations associated with a semantic interpretation, and vice versa;

- step 4 is to produce, on prosodic ground, better semantic descriptions than the one which were initially tested.

The outcomes of such a procedure cannot be detailed here, but some lessons can be taken, notably that:

- matching prosody with interpretation is due to fail every time the interpretative categories which are tested are too wide;

- it is only by a constant and consistent amelioration of the semantic/pragmatic characterization of the data that prosodic contours and prosodic features can be matched with semantic/pragmatic interpretation.

All in all however, two interesting conclusions can be drawn from working with this methodology for some years;

- the first one is that prosody is to semantics and linguistic pragmatics what the microscope has been to biology;

- the second is that proving any match between a prosodic feature (or contour) and an interpretation requires a large amount of authentic date and the use of automated classification techniques.

\section{Automated discrimination of prosodycally features or contours}

Given the huge variety of voices, recording conditions, left and right contexts, and more importantly the possibility of expressing simultaneously various emotions, feeling, postures and comments, matching prosodic features with interpretative ones and proving the existence of such or such matching requires specialized techniques whose basic goal is not the matching itself but the demonstration of the capacity to automatically discriminate between various interpretations. Doing in an automated manner and with an undisputable technique, what can be done by hand so to say but cannot then be proved. It requires large data banks of word uses to obtain reliable results.

Such a program has been implemented in Orléans since 2013 by a consortium of four laboratories and the joint work of linguists, speech processing specialists, computer scientists and mathematicians; The DIASEMIE" program dealing with "automated prosodic

\footnotetext{
${ }^{7}$ At this stage, such observations remain conjectural and cannot be considered as proofs.

${ }^{8}$ DIASEMIE stands for "DIscrimination Automatique des Sens d'Emplois des Mots par l'Intonation"
} 
discrimination of word use interpretations and meanings" has been empirically centered on the uses of French 'oui' (with 2400 extracted uses) and to a lesser degree English 'yes', both extracted from corpora of mainly dialogical contexts, with the goal of mapping labeled semantic and pragmatic features with prosodic ones. After this extraction and constitution of the data bank of uses, it has basically followed a procedure similar the non-automated approach already presented, namely a pragmatic/semantic analysis leading to an identification of interpretative features and use-types associated with "oui" and the interpretative characterization of individual uses, while the sound form was in parallel decomposed into $20 \mathrm{~ms}$ segments whose vectorization is assured by a set of prosodic parameters, allowing to test the correspondence between interpretative characterization and prosodic features through the use of classification algorithms (including a Darwinian selection of the most relevant prosodic parameters). The outcomes of this test are:

- a measure of the rate of correct discrimination/recognition of interpretative features;

- a list of errors of classification, with all the uses which could not be attributed to the supposedly correct interpretative category;

- $\quad$ an identification of the prosodic parameters which allow optimal classification.

These first results allow the start of a shuttle process which in this case is taking the form of an automated analysis of the classification errors, in which the linguists can either infirm or confirm the possible error, and can also improve their semantic/pragmatic characterization of the data into more precise interpretative categories and to a better mapping of the relation between prosodic forms and interpretation.

The first test of the efficiency of this automated chain of treatment on a reduced corpora was achieved (Gharbi and al 2015) to measure the discriminability of the convinced/unconvinced interpretative feature which was presented in the previous section, showing that the discrimination of this pragmatic/semantic feature could be achieved with a $80 \%$ success prior to the shuttle process, corrected to $97 \%$ after the shuttle process, the machine proving to be more reliable for the characterization of mixed uses than the initial human semantic expertise ${ }^{9}$.

One of the main outcome of the DIASEMIE program has been the creation of a set of computer tools (MaT, DiAnalor, ExtraPraat, etc.) for each step of the discriminating process, which amon other things has lead to the reduction of human time work by $85 \%$.

Given the necessity to build up and to analyze hundreds if not thousands of uses to improve the reliability of the results, the fact that the whole chain of treatment from data extraction to the shuttle process is now fully automated makes it possible ultimately to achieve a full mapping of both FLP and NSP, even if it must be stressed out that such a technical progress however cannot produce such an outcome without the collective mobilization of available semantic and pragmatic expertise. This is why, one of the goals of the forthcoming SEMORAL program ${ }^{10}$ will be to make available on line to the Linguistic Pragmatic community all these tools and the procedural know-how associated to them, allowing researchers on any type of lexical items, construction or sentence-type ${ }^{11}$ from any language to

\footnotetext{
${ }^{9}$ In other words, uses of oui combining for instance an initial manifestation of a lack of conviction (typically prior to the uttering of the oui itself) with a finally convinced oui, had been characterized as unconvinced uses because of the presence of a manifestation of a lack of conviction, meanwhile the machine, whose only input is the sound form of the oui correctly recognized them as convinced ones. Analysts have indeed a tendency to interpret a use as a whole, and not only the sound segment alone.

${ }^{10}$ The SEMORAL project will concern prosodic discrimination at all interpretative levels, in other words wodlevel (FLP), sentence-type and utterance level, contribution and discourse level, notably anaphora resolution. It associates 3 linguistic laboratories, 2 NLP laboratories and a laboratory specialized in speech processing.

${ }^{11}$ The SEMORAL project itself will study the discrimination of NSP of imperative sentences (e.g. classical directive values such as allowing, asking, ordering, giving a piece of advice, challenging, heartening, etc.).
} 
test their own data and pragmatic characterizations, and allowing the scientific community to make and test valuable generalizations and cross-linguistic comparisons.

\section{Conclusion}

The fact that intonation, in the broader sense of the term, plays an important role in the interpretation of what is said will come as no surprise to most people. The fact that this role may be fully understood and analyzed through the automated study of the discrimination of non-structural prosody - including at word-level (FLP) when the $\pi$ contours of use-types are lexicalized together with the prosodic comment - may on the contrary be a turning point within linguistics, whose efforts and attempts to map prosodic form with interpretation have remained comparatively limited.

More importantly, the fact that such a mapping may be proven both to require and to allow a considerable improvement of the precision of semantic descriptions, and especially of the pragmatic layer of linguistically-driven meaning is of paramount importance. For it seems indeed that failures in the matching of prosodic form with interpretation may always be proven to be caused by semantic roughness of initially tested meanings. And consequently that taking meaningful prosody into account seriously, first of all by working on oral data, has the same effect on linguistics that the microscope and telescope had respectively on biology and astronomy.

As importantly, because prosodic constraints on interpretation are indisputably linguistics constraints on interpretation may be proven to affect both semantic and pragmatic information, with prosodicing comments appearing to have a strongly dialogical/interactional nature $^{12}$, their existence not only forces us to deeply reconsider the nature of the semantic/pragmatic interface, but shows and proves that the way this issue has been framed since the seventies is flawed by the fact that any uttered (and intoned) sentence or sign is associated with a prosodic form which contains, constrains and provides pragmatic interpretation at the very start of the interpretative process: pragmatic interpretation is thus not a downstream process that would take place once a purely linguistic process of interpretation has already and autonomously taken place, as claimed by the tenants of "downstream" pragmatics. And on the opposite, it may be proven on prosodic ground that providing information about the world and providing information about one's attitude toward the world or providing information about the attitude of the interlocutors regarding the speaker's attitude (and the world) is a linguistically-driven process all along, which could become a new chapter in the history of Linguistic Pragmatics.

\section{References}

Barnes, Betsy. 1995. Discourse Particles in French Conversation: (eh) ben, bon and enfin. The French Review 68 (5). 813-821.

Beeching, Kate. 2007. La co-variation des marqueurs discursifs bon, c'est-à-dire, enfin, hein, quand même, quoi et si vous voulez : une question d'identité ?. Langue française 154 (2). 7893.

Bertrand, Roxane and Chanet, Catherine. 2005. Fonctions pragmatiques et prosodie de enfin en français spontané. Revue de Sémantique et Pragmatique 17. 41-68.

Preliminary work on such NSP has shown as expected that NSP contours are providing more complex and fine grained information than mere illocutionary values.

12 they do not only describe the relation of the speaker to what is at stake but, polyphonically, the way (s)he relates to those of all interlocutors. 
Buchi, Eva and Städtler, Thomas. 2008. La pragmaticalisation de l'adverbe enfin du point de vue des romanistes («Enfin, de celui des francisants qui conçoivent leur recherche dans le cadre de la linguistique romane »). Durand (Jacques)/Habert (Benoît)/Laks (Bernard) (éd.), Congrès mondial de linguistique française (Paris, 9-12 juillet 2008). Recueil des résumés, CD-ROM des actes, Paris, Institut de linguistique française. 159-171.

Cadiot, Anne et al. 1985. Enfin, marqueur métalinguistique. Journal of pragmatics 9. 199239.

Calhoun, Sasha and Schweitzer, Antje. 2012. Can Intonation Contours be Lexicalised? Implications for Discourse Meanings. Gorka, Elordieta and Pilar, Prieto (eds.) Prosody and Meaning (Trends in Linguistics), De Gruyter Mouton. 271-328.

Hansen Mosegaard, Maj-Britt. 2005. From prepositional phrase to hesitation marker: The semantic and pragmatic evolution of French enfin. Journal of Historical Pragmatics 6 (1). 3768.

Lacheret, Anne. 2013 sous presse. Prosodic clustering in speech : from emotional to semantic processes. Emotions in language, Lüdke U. (ed.), Amsterdam: Benjamins.

Lacheret-Dujour, Anne and Beaugendre, Frédéric. 2002. La prosodie du français. Paris: CNRS Editions.

Ladd, D. Robert. 2008. Intonational Phonology, 2nd edition, Cambridge: Cambridge University Press.

Mertens, Piet. 2008. Syntaxe, prosodie et structure informationnelle : une approche prédictive pour l'analyse de l'intonation dans le discours. Travaux de Linguistique 56 (1). 87-124.

Morel, Marie-Annick and Danon-Boileau, Laurent. 1998. La grammaire de l'intonation, l'exemple du français oral. Paris: Ophrys.

Nemo, François and Petit, Mélanie. 2015. Prosodie non-structurale et plurisémie. Revue de Sémantique et Pragmatique 37. 85-102.

Nemo, François and Petit, Mélanie. 2012. Sémantique des contextes-types. Saussure, L. de and Rihs, A. (eds), Etudes de sémantique et pragmatique françaises. Berne: Lang, 379-403.

Nemo, François. 2000. Enfin, encore, toujours entre indexicalité et emplois. Englebert A. et al (éd.), Actes du XXIIe Congrès international de linguistique et de philologie romanes, (Bruxelles, juillet 1998), Tübingen, Max Niemeyer Verlag, vol. 7. 499-511.

Nemo, François. 1999. The Pragmatics of Signs, the Semantics of Relevance and the Semantic/Pragmatics Interface. Ken Turner, The Semantics-Pragmatics Interface from Different points of View, CRiSPI Series, Amsterdam: Elsevier Science. 343-417.

Nemo, François. 2006. The Pragmatics of Common Ground. From Common knowledge to Shared Attention and Social Referencing. Lexical Markers of Common Grounds (Studies in Pragmatics, Volume 3) A. Fetzer and K. Fischer (Eds). Amsterdam: Elsevier Science (224 pages). 143-158.

Noda Hiroko. 2005. L'emploi des mots du discours et la prosodie: le cas de hein. Proc. Interface Discours Prosodie 2005, Aix-en-Provence, 8-9 septembre 2005.

Paillard, Denis. 2003. À propos de enfin. Combettes, Bernard, Schnedecker, Catherine and Theissen, Anne (éds) 2003. Ordre et distinction dans la langue et le discours. Actes du Colloque international de Metz (18, 19, 20 mars 1999). Paris: Champion. 387-408.

Petit, Mélanie. 2009. Discrimination prosodique et représentation du lexique : application aux emplois des connecteurs discursifs. Thèse de doctorat. Université d'Orléans. 